Part 1

Understanding Human Rights 



\section{Researching and studying human rights: interdisciplinary insight}

\section{Damien Short}

Since 1948, the study of human rights has been dominated by legal scholarship that has sought to investigate the development of human rights law, emerging jurisprudence, regional systems, the decisions and recommendations of human rights mechanisms and institutions and to a lesser extent the 'compliance gaps' between state commitments and actions. Even so, in all of these spheres there are elements that cannot be fully understood through a purely legal lens, moreover, if we understand 'human rights' more broadly, and look into the practical world of human rights work and human rights discourse, advocacy and activism, then we need to go beyond legal analysis. Indeed, to understand the world of human rights in both theory and practice requires interdisciplinary insight, as it covers an enormous range of social, political, economic and environmental issues. In this chapter, I will outline the contributions of two disciplines that were slow to contribute to the field of human rights but which offer vitally important insights that can guide both academic research and human rights advocacy.

\section{Sociological insights}

Sociology was initially sceptical with the normativity that is attached to human rights along with the claim of universality, which saw a sociology of citizenship effectively act as a substitute for a sociology of human rights. In a series of seminal contributions in the 1990s, Bryan Turner argued that the concept of citizenship, however, is closely linked with the modern nation state, a political form that has been infected with the problems of imperialism, globalisation, migrant workers, refugees, and Indigenous peoples (Short 2009). In a key essay for the journal Sociology, Turner (1993) suggested that globalisation has created problems that are not wholly internal to nation states and that consequently we should extend sociological inquiry to the concept of human rights. While few sociologists have attempted (like Turner) to develop a foundational social theory of human rights, there is now a growing body of research that embraces a more social constructionist view of human rights. 
From a social constructionist perspective universal human rights should be seen as 'historically and socially contingent, the product of a particular time, place, and set of circumstances, and a work in permanent progress' (Morris 2006, 26). A sociological approach to rights discourses, practices, and struggles is necessary to identify the mechanisms that translate social phenomena into rights disputes. Yet, viewing rights this way suggests that we must pay due attention to the social actors involved in their invention/construction if we are to understand rights regimes fully.

Within this broad social constructionist sociology we can see an important dimension of sociological enquiry begin to emerge, i.e. the role of power in the domain of human rights. Human rights scholar Michael Freeman (2002), in a major interdisciplinary contribution to the area, identifies rights institutionalisation as a social process and he also displays an acute awareness of the role of power in that process, which he sees as perhaps the major sociological contribution. He writes:

The institutionalisation of human rights may ... lead, not to their more secure protection, but to their protection in a form that is less threatening to the existing system of power. The sociological point is not that human rights should never be institutionalised, but, rather, that institutionalisation is a social process, involving power, and that it should be analysed and not assumed to be beneficial (Freeman 2002, $85)$.

Freeman further argues that the social sciences have been 'excessively legalistic' and overemphasised the UN system whilst neglecting to look deeper into the role of powerful global institutions and global power politics, most notably the G7, the Bretton Woods institutions, and the foreign policy of the US, in both the violation and construction of human rights (Freeman 2002, 177). The discipline of sociology is well placed to investigate the role of power in this regard.

Social research has shown how rights should be viewed as instrumentally useful strategic resources invoked by social actors in competition for power in domestic and international arenas (Short 2009). Rights can be constructed through the interplay of domestic and international forces and will be reinforced as long as otherwise powerless social actors find no other alternative but to engage in rights talk. Sociology may be the discipline best equipped to discuss the social forces that underline the genesis of such rights and the social struggles from which they materialise (Short 2009). A primary task for sociologists is to become intimately familiar with the advocates, their claims, and the social processes through which rights are constructed, while being careful to balance claims for universal applicability with the empirical reality of social and cultural diversity in the world. Sociological researchers are also well placed to examine the 'considerable gap between the recognition of the need for protection and its achievements in practice' (Morris 2006, 3). Sociological 
researchers should ask some very important questions such as: How are rights socially constructed - by whom, for whom, and in what social context? How and why do particular social actors and groups claim and access rights? How are rights affected by the social, political, and economic context in which they emerge and operate? What role is played by social structures - are they enabling, constraining, or both? To what extent are rights guaranteed or limited by the law? Have power relations affected the construction and functionality of rights? Whose interests do rights actually work to protect?

In summary, the discipline of sociology is well equipped to expose, discuss, and possibly amend obvious limitations in existing conceptions of rights, especially the formal legalistic dimensions, the limitations of which, as we shall see later, are something that social anthropologist Richard Wilson is also concerned to 'move beyond' (1997). Such sociological research is now gathering pace. Indeed, the British Sociological Association now has a 'Sociology of Rights' study group, from which has already emerged a major contribution to the subfield entitled 'Sociology and Human Rights: New Engagements' (Hynes, Lamb, Short, and Waites 2011).

\section{Anthropological insights}

The issue of cultural relativism has of course influenced both sociological and anthropological perspectives on human rights. It was a major factor that led sociology to take such a long time to engage with the phenomena at all; while anthropology, on the other hand, was an influential voice at the outset of the international codification of human rights norms (Short 2009, 97).

The discipline of anthropology has evolved to be concerned with the study of the entire range of cultures and societies in the world. Given such scope, there are significant points of convergence between anthropology and sociology. Yet in the early stages of its development the discipline tended to focus on non-Western 'primitive' societies, which led to important differences between the disciplines (Short 2009, 97). Sociology historically tended to focus on Western societies, which thus generated methodological and theoretical differences between the two disciplines. For example, when Western sociologists studied their own society they could take much context for granted before hypothesising about their data, while anthropologists studying other cultures could make few safe assumptions and consequently developed an holistic methodology that emphasised that each social entity or group has its own identity that is distinct and not reducible to individual constituent parts. Consequently, anthropology would not assume that all cultures shared the same values, which is the fundamental ontological position that guided the discipline's early attitude towards the notion of universal human rights.

Consequently a key school of thought for those anthropologists seeking to engage with the world of human rights sought to use the discipline's 
ethnographic methodology to explore and investigate the 'social practice of human rights' or, as Richard Wilson puts it, 'the social life of rights' (1997). Wilson, a social anthropologist, agrees with the main thrust of the sociological approaches that were discussed above, arguing that social scientists should be primarily concerned with analysing rights as socially constructed phenomena. He writes:

The intellectual efforts of those seeking to develop a framework for understanding the social life of rights would be better directed not towards foreclosing their ontological status, but instead by exploring their meaning and use. What is needed are more detailed studies of human rights according to the actions and intentions of social actors, within wider historical constraints of institutionalised power. (Wilson 1997, 3-4)

Taking up this call, researchers began to focus on an increase in negotiations and claims made by various social groups in a language of 'rights'. A trend began to emerge in which long-established theoretical debates about concepts such as rights, justice, and citizenship began to engage with empirical 'data' that contextualises rights-claiming processes (Short 2009). Anthropologists started to advocate the need to explore how exactly universal concepts were being used in local struggles. In essence, the relationship between culture and rights was seen as an issue to be studied empirically. The thrust of this approach is thus descriptive and makes no claim to endorse the universality of human rights. It is an effort to uncover how human rights actually function in an empirical sense, to uncover what they mean to different social actors in different social contexts. More attention was gradually being paid to empirical, contextual analyses of specific rights struggles. This intellectual strategy sought to record how individuals, groups, communities, and states use rights discourse in the pursuit of particular ends, and how they become enmeshed in its logic (Short 2009, 98).

Anthropology's relativistic perspective was borne out of a detached scientific methodology that frequently observed a plethora of value systems in its research 'subjects'. This 'detached' approach, however, did not last as the dominant perspective. While many anthropologists were able to maintain an 'objective' detachment from their research subjects, increasingly this approach gave way to immersion and empathy, which in turn led to political activism on behalf of the subjects.

Those who advocated such an approach argued that anthropological understandings of specific cultural processes, which are embedded in wider (what sociologists would term 'structural') social power relationships, should be used to bolster specific endeavours for social change and/or to assist specific marginalised peoples, populations, or groups in resisting threats to their survival (Short 2009). This approach views human rights as a useful tool for serving an ethical commitment towards threatened peoples and cultures. The effectiveness 
of human rights as a tool in this sense can be greatly improved through more expansive and inclusive definitions. Thus, there is a normative suggestion within this approach that anthropologists should work to expand the definitions of human rights so as to increase their effectiveness for marginalised groups and cultures—an approach termed 'emancipatory cultural politics' (Short 2009, 98). This approach, which encourages anthropological engagement with human rights discourse as a political strategy for the protection of threatened populations, was perhaps the first major disciplinary current to emerge in the anthropology of human rights. Perhaps the most notable recent research within this broad approach is that of Shannon Speed, which she has termed 'critically engaged activist research' (Speed 2006, 66). This approach is concerned to embrace the issues raised by the social actors, not shy away from engagement and commentary, and in fact warns against an overly detached anthropology of human rights (Speed 2006, 66). The focus of the research is not just about research on human rights in the particular site-Chiapas, Mexico-but also advocacy for human rights there. Consequently, it could be suggested that such research does not fall into the trap of forgetting the 'human' in human rights. For the social actors suffering injustice, human rights are much more than an academic curiosity (Short 2009).

\section{Conclusion}

We have seen how from an initial position of scepticism there is now a growing body of research emerging from both sociology and anthropology that seeks to explore the construction, meaning, use and functioning of rights, and for some, the secondary goal is to use this data to work for the protection of human rights through critically engaged activist research. It is this latter approach which has informed all of my teaching on the MA Understanding and Securing Human Rights at the Institute of Commonwealth Studies. Furthermore, in addition to the knowledge gleaned from legal, philosophical, and political approaches to the study of human rights, when I teach our Understanding Human Rights module, I strongly urge students to embrace interdisciplinary and, in particular, anthropological and sociological studies that explore the 'social life of rights', since it is only through such studies that we can hope to understand fully the practice of human rights in the modern world.

\section{Bibliography}

Freeman, M. (2002) Human Rights: An Interdisciplinary Approach (Malden, MA: Polity).

Hynes, P., M. Lamb, D. Short and M. Waites (2011) Sociology and Human

Rights: New Engagements (London: Routledge).

Morris, L. (ed.) (2006) Rights: Sociological Perspectives (Abingdon: Routledge). 
Short, D. (2009) 'Sociological and Anthropological Approaches', in M. Goodhart (ed.), Human Rights Politics and Practice (Oxford: Oxford University Press), chapter 6.

Speed, S. (2006) 'At the crossroads of human rights and anthropology: toward a critically engaged activist research', American Anthropologist 108 (1), pp. 66-76.

Turner, B. S. (2006) Vulnerability and Human Rights (University Park, PA: The Pennsylvania State University Press).

Wilson, R. (1997) 'Human rights, culture and context: an introduction', in R. Wilson (ed.), Human Rights, Culture and Context: Anthropological Perspectives (London: Pluto Press), pp. 1-27. 